Investigations

\title{
Effects of Recombinant Toxin Phospholipase D in Cardiac Muscle of Rats
}

\author{
${ }^{1}$ Joao Victor Capelli Peixoto, ${ }^{2}$ Fernando Augusto Lavezzo Dias, \\ ${ }^{3}$ Carlos Estevan Nolf Damiani, ${ }^{4}$ Ilana Kassouf Silva, \\ ${ }^{5}$ Silvio Sanches Veiga, ${ }^{6}$ Julio Cesar Francisco and ${ }^{7}$ Rosalvo Tadeu Hochmueller Fogaça \\ ${ }^{1-4,7}$ Physiological Sciences, Federal University of Parana, Brazil \\ ${ }^{5}$ Cell Biology, Federal University of Parana, Brazil \\ ${ }^{6}$ Biotechnological Processes, PUC-PR, Brazil
}

Article history

Received: 27-11-2014

Revised: $30-03-2015$

Accepted: 16-05-2015

Corresponding Author: Joao Victor Capelli Peixoto Physiological Sciences, Federal University of Parana,Brazil Email: jjpeixoto83@gmail.com

\begin{abstract}
Loxoceles spiders gender are worldwide spread and its bites can cause dermonecrosis or even a systemic effect (hemolysis, kidney and liver injury). It is believed that phospholipase $\mathrm{D}$, the main component present in the venom, could be responsible for the injury. In this study, we used a recombinant form of phospholipase D (rLiD1) and evaluated its direct and systemic effects on the contractility of papillary muscles and in the left intra ventricular pressure of isolated perfused hearts, respectively. In papillary muscle directly exposed to rLiD1 no effects on force, maximum speed of contraction $\left(\mathrm{df} / \mathrm{dt}_{\max }\right)$ or relaxation $\left(\mathrm{df} / \mathrm{dt}_{\min }\right)$ were observed. In isolated perfused heart, the peak of systolic pressure and the rate of relaxation $\left(\mathrm{dP} / \mathrm{dt}_{\text {min }}\right)$ were reduced in animals treated with rLiD1. However, the maximum speed of pressure developed during contraction $\left(\mathrm{dP} / \mathrm{dt}_{\max }\right)$ was unaffected. These data suggest that rLiD1 did not affect directly the excitation contraction coupling or the contractility of the myocardium but its systemic effect can induce reduction in the cardiac performance.
\end{abstract}

Keywords: Cardiac Muscle, Excitation Contraction Coupling, Phospholipase D

\section{Introduction}

Loxoscelic accident or loxoscelism is the designation of the clinical outcome developed by individuals bitten by spiders of the genus Loxosceles (Futrell, 1992). This condition can manifest as dermonecrotic (84-97\% of cases) or as a systemic outcome (3-16\% of cases) (Barbaro et al., 1992). The systemic effects are potentially fatal and should be medically addressed (Peterson, 2006).

In Brazil, the Loxosceles spider most closely related to accidents are the Loxosceles gaucho, Loxosceles laeta and Loxosceles intermedia. Regardless of the species, this poison can cause dermonecrotic and systemic outcome (Barbaro et al., 2005; Chaim et al., 2011; da Silva et al., 2004).

The dermonecrosis is characterized by a rash in the bite region (Futrell, 1992). Clinical findings of the systemic effects are hemolytic anemia, thrombocytopenia resulting from platelet aggregation and intravascular coagulation, events that culminate in decreased hematocrit (Peterson, 2006). The ELISA method detected circulating antigens in kidney, heart, lung and liver of poisoned rats (Dias-Lopes et al., 2010). The main reason of death in cases of loxoscelism is due to acute renal failure (Futrell, 1992; Peterson, 2006).

Studies have shown that the component of the venom responsible for dermonecrotic effects is phospholipase D because this toxin hydrolyzes sphingomyelin and glicerophospholipids (Chaim et al., 2011; Lee and Lynch, 2005).

The phospholipase D interacts with and degrades phospholipids, generating ceramide-1-phosphate and lysophosphatidic acid, initiating a cascade that allows the calcium to enter the cell by the L-type channels contributing to hemolysis (Chaves-Moreira et al., 2011).

Hearts of mice poisoned by phospholipase $\mathrm{D}$ have increased the calcium current and L-type channels also increase the calcium transient, although the force of systolic contraction is decreased (Dias-Lopes et al., 2010).

There is only a few data relating the effects of recombinant toxin phospholipase $\mathrm{D}$ in cardiac muscle. In this study, we investigated the direct and systemic effects of rLiD1 in cardiac muscle of the rat. 


\section{Materials and Methods}

Animals

Thirty-four male Wistar rats, weighing 250-300 g were used. The animals were kept in cages under controlled conditions of temperature and light-dark cycle of $12 \mathrm{~h}$, with free access to food and water. The Animal Experimentation Ethics Committee of the Biological Sciences Section at Federal University of Paraná approved all experimental protocols used in this study (AEEC-591). Animals were anesthetized $\left(50 \mathrm{mg} \mathrm{kg}^{-1}\right.$ of ketamine and $10 \mathrm{mg} \mathrm{kg}^{-1}$ of xylazine, injected intra peritoneally). After opening of chests the hearts were removed and transferred to a Becker containing $20 \mathrm{~mL}$ of Ringer's solution. This solution had the following composition (in $\mathrm{mM}$ ): $\mathrm{NaCl}=$ 110; $\mathrm{KCl}=4.0 ; \mathrm{CaCl}_{2}=2.0 ; \mathrm{MgCl}_{2}=2.0 ;$ TRIZMA $=10$ and glucose 11, pH adjusted to 7.4 with $\mathrm{NaOH}$ or $\mathrm{HCl}$ and gassed with pure oxygen.

\section{Recombinant Toxin Phospholipase D(rLiD1)}

The recombinant toxin was provided by the Laboratory of Extracellular Matrix and Poisons Biotechnology, division of Biological Science from The Federal University of Paraná. The toxin was produced as described previously (Chaim et al., 2006; ChavesMoreira et al., 2011). The integrity, purity and quality of rLiD1 was checked by electrophoresis (Harlow and Lane, 1988) and its activity was measured using the Amplex Red Assay Kit (Molecular Probes, Eugene) as previously described (Appel et al., 2008; ChavesMoreira et al., 2011).

\section{Experimental Design}

Rats were randomly separated into four groups, each containing acontrol group and an experimental group:

Group 1: Isolated perfused heart

Group 2: Isolated papillary muscle

\section{Isolated Perfused Heart}

The animals in this group were pretreated with rLiD1 $\left(240 \mu \mathrm{g} \mathrm{kg}^{-1}\right)$ (Lucato et al., 2011) administered intra peritoneally. Animals of the control group were injected with equivalent volume of PBS. The evaluation of cardiac performance of these animals was done $24 \mathrm{~h}$ after injection.

As previously described (Dianat et al., 2014; Prendes et al., 2014), the heart was quickly removed and transferred to a Langendorff perfusion system where steel cannula was secured to the aortic stump by suture, allowing immediate perfusion with Ringer's solution composition already described, continuously oxygenated, maintained $37^{\circ} \mathrm{C}$ and $\mathrm{pH} 7.4$, immersed in Ringer's solution of identical composition. For measurement of left ventricular pressure, the left atrium was removed and a plastic-made balloon film connected to a pressure transducer (WPI-rBPI) was inserted into the left ventricle through the mitral valve. The volume of the balloon was gradually adjusted to obtain the maximum value in the volume/pressure generated by myocardial contraction. The data were obtained using an acquisition system PowerLab 4/30, AD Instrument and subsequently analyzed using Lab Chart version 7.3.7 software.

\section{Isolated Papillary Muscle}

After thoracotomy, the heart was removed and transferred to a Petri dish containing Ringer's solution, as previously described (De Campos et al., 2014; Szkudlarek et al., 2014). The papillary muscles were immediately removed using ophthalmological scissors and mounted horizontally in a chamber with capacity for three milliliters containing Ringer's solution at a temperature of $37^{\circ} \mathrm{C}$ and $\mathrm{pH} 7.4$, continuously oxygenated. The myocardial portion of the papillary muscle was fixed to a stationary clip while the tendinous portion was attached to a force transducer (Fort 10 WPI, Transduction Laboratories Co.). The papillary muscles were stimulated $(0,5 \mathrm{~Hz})$ with supra-threshold voltage pulses (10 to $15 \mathrm{~V})$, with duration of a maximum of five milliseconds (ms) through a pair of platinum electrodes positioned along the entire length of the muscle. Under these conditions, the muscles were maintained for a stabilization period of 30 min and then the experimental protocols were performed. The data were collected using an acquisition system PowerLab 4/30, (AD Instrument) and subsequently analyzed using Lab Chart version 7.3.7 software.

To evaluate the possible effect of phospholipase D on the strength ofisometric contraction was added to chamber increasing concentrations ofphospholipase D (8.3 and $\left.16.6 \mathrm{ugmL}^{-1}\right)$. We evaluated the effects of toxin for $30 \mathrm{~min}$. The experiments were performed in the control group with equivalentvolume of PBS.

\section{Statistical Analysis}

Data are presented as mean \pm standard error of the mean. Comparisonina single experimental condition between tratedand control groups, will be done using Student's t-test. For multiple comparisons, in the same experimental condition ANOVA willbe used. For data analysis and plotting GraphPad Prism 5Software(San Diego, CA, USA) software wasused. Statistically significantdifference between groups will be accepted when the probability of the null hypothesis is lessthan or equal to $5 \%(\mathrm{p} \leq 0.05)$.

\section{Results}

The peak of left ventricle systolic pressure developed by isolated perfused hearts (LIVP) is shown in the Fig. 13. Significantly differences between control and animals treated with rLiD1 were observed. The LIVP in control and treated groups were $137,3 \pm 4,5 \mathrm{mmHg}$ and $123,7 \pm 3,4$ $\mathrm{mmHg}(\mathrm{p}=0,031)$, respectively. 
A

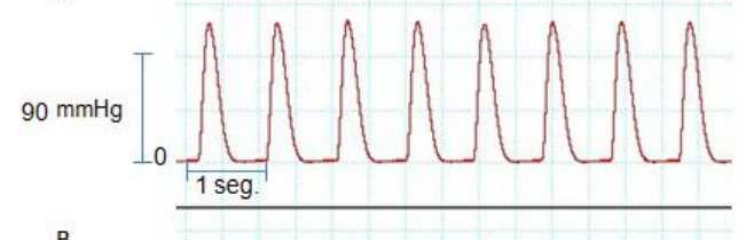

B

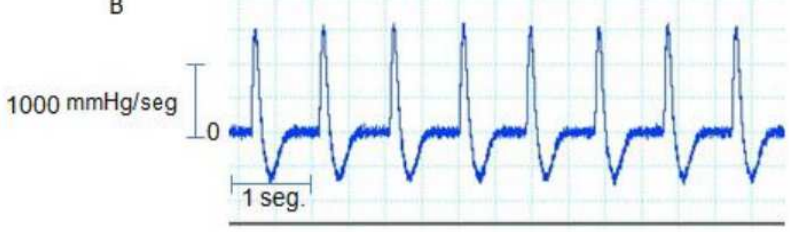

Fig. 1. Typical record of the left intra ventricular pressure of isolated perfused heart in (A) and the calculated first derivative in $(\mathrm{B})$

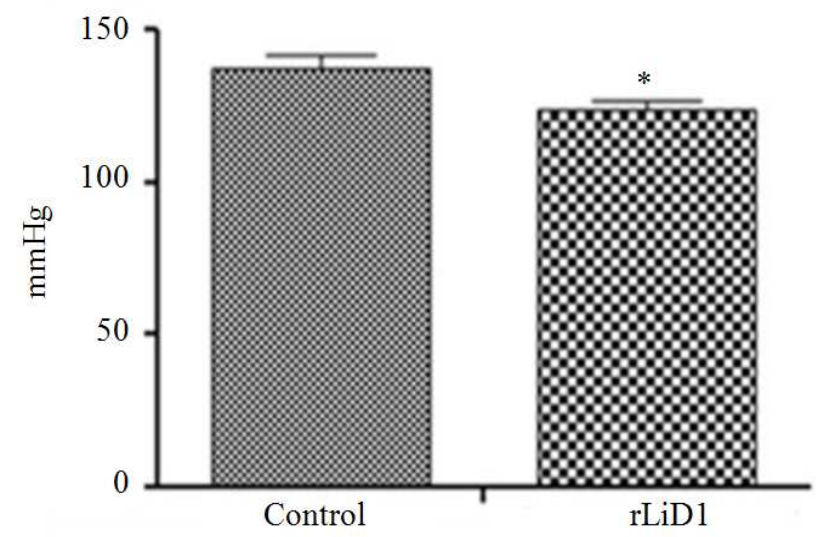

Fig. 2. Peak of left ventricle systolic pressure of isolated perfused heart from control and animals treated with rLiD1. The results are expressed as mean \pm sem. * represent statistical significant difference between groups. In the control and in treated animals the values were, respectively $137,3 \pm 4,5$ and $123,7 \pm 3,4$ mmHg. $(\mathrm{p}=0.031)$

However, no differences in the maximal speed of pressure development by the left ventricle $\left(\mathrm{dP} / \mathrm{dt}_{\max }\right)$ had been observed $(1536,5 \pm 55,7 \mathrm{mmHg} / \mathrm{sec}$ in the control group vs $1392,3 \pm 37,6 \mathrm{mmHg} / \mathrm{sec}$ in $\mathrm{rLiD} 1$ treated group, Fig. 3A). Also, the maximal speed of pressure decrease in left ventricle $\left(\mathrm{dP} / \mathrm{dt}_{\text {min }}\right)$ was significantly reduced in treated group (Fig. $3 \mathrm{~B}$ ). The $\mathrm{dP} / \mathrm{dt}_{\min }$ in the control and in the treated group were $-819,1 \pm 29,0$ $\mathrm{mmHg} / \mathrm{sec}$ and $-710,3 \pm 23,0(\mathrm{p}=0,010)$, respectively.

The data obtained in isolated papillary is showed in Table 1. The maximal force developed, maximal speed of contraction $\left(\mathrm{df} / \mathrm{dt}_{\max }\right)$ and the maximal speed of relaxation $\left(\mathrm{dp} / \mathrm{dt}_{\min }\right)$ were unaffected by the presence of $\operatorname{rLiD} 1\left(8,3\right.$ or $\left.16,6 \mu \mathrm{gmL}^{-1}\right)$.

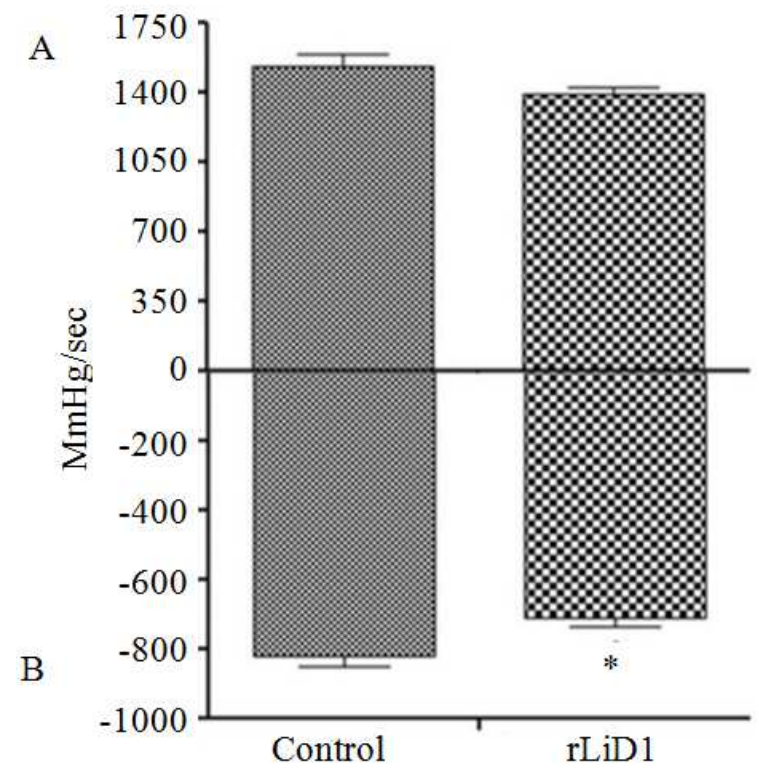

Fig. 3. Effects of rLiD1 on the maximal speed of the left intra ventricular pressure during the contraction $\left(\mathrm{dP} / \mathrm{dt}_{\max }\right)$ (A) and relaxation $\left(\mathrm{dP} / \mathrm{dt}_{\min }\right)$ (B). The results are expressed as mean \pm sem. *represent statistical significant difference between groups. In the control and in $\mathrm{rLiD} 1$ treated group the $\mathrm{dP} / \mathrm{dt}_{\max }$ and $\mathrm{dP} / \mathrm{dt}_{\min }$ were, respectively (in $\mathrm{mmHg} / \mathrm{sec}$ ) $1536,5 \pm 55,7$ and $1392,8 \pm 37,6(\mathrm{p}=0.0508)$; and $-819,1 \pm 29,0$ and $710,3 \pm 23,0(\mathrm{p}=0,010)$

Table 1. The direct effects of $\mathrm{riD} 1\left(8,3\right.$ and $\left.16,6 \mathrm{ug} \mathrm{mL}^{-1}\right)$ on the twitch, maximal speed of contraction $\left(\mathrm{df} / \mathrm{dt}_{\max }\right)$ and relaxation $\left(\mathrm{df} / \mathrm{dt}_{\min }\right)$ of isolated papillary muscles. The twitch force is expressed in $\mathrm{mN} / \mathrm{mm}^{2}$. $\mathrm{df}^{\mathrm{d}} / \mathrm{t}_{\max }$ and $\mathrm{df} / \mathrm{dt}_{\min }$ in $\mathrm{mN} / \mathrm{mm}^{2} / \mathrm{sec}$. The data is expressed as mean \pm sem

\begin{tabular}{lllll}
\hline & & Ringer & $8,3 \mu \mathrm{g} \mathrm{mL}^{-1}$ & $16,6 \mu \mathrm{g} \mathrm{mL}^{-1}$ \\
\hline Force & Control & $13,1 \pm 2,0$ & $12,3 \pm 1,3$ & $10,6 \pm 0,6$ \\
& rLiD1 & $18,6 \pm 4,3$ & $18,4 \pm 2,7$ & $15,7 \pm 1,9$ \\
$\mathrm{df} / \mathrm{dt}_{\max }$ & Control & $154,5 \pm 25,5$ & $149,6 \pm 17,9$ & $144,4 \pm 9,9$ \\
& rLiD1 & $240,0 \pm 43,8$ & $243,6 \pm 38,4$ & $232,2 \pm 34,4$ \\
$\mathrm{df}_{\mathrm{d}} \mathrm{dt}_{\min }$ & Control & $-132,5 \pm 33,0$ & $-110,0 \pm 11,5$ & $-113,0 \pm 7,9$ \\
& rLiD1 & $-184,7 \pm 40,8$ & $-204,0 \pm 39,8$ & $-186,6 \pm 33,6$ \\
\hline
\end{tabular}

\section{Discussion}

Sphingomyelin is the main substrate of phospholipase D. Sphingomyelin products such as sphingosine and ceramide modulate potently cell activity by the activation of a $G$ protein, triggering a cascade of events leading changes in intracellular $\mathrm{Ca}^{++}$ concentration which affects the activity of enzymes involved in the regulation of $\mathrm{Ca}^{++}$and modulating intracellular $\mathrm{Ca}^{++}$levels (Tornquist et al., 2004). Ceramide can be phosphorylated by ceramide kinase originating ceramide-1-phosphate. Ceramide-1phosphate can bind to sphingolipids receptors present 
in the cell membranes activating PKC and in a dosedependent manner, increases the influx of $\mathrm{Ca}^{++}$ (Hannun, 1996).

Cardiac troponin I can be phosphorylated by PKC (Roman et al., 2004; Dong et al., 2012). The calcium sensitivity of the myofilaments is decreased by the phosphorilation of Troponin I resulting in the reduction of the speed of cross bridge cycle. In other words, PKC phosphorylates troponin I and negatively regulates cardiac contraction (Roman et al., 2004). This could explain the reduction in the peak of left ventricle systolic pressure observed in the present work. Also, mice envenomed with crude Loxoceles venom showed a reduction in the force production (Dias-Lopes et al., 2010). The reduction in the maximum speed of relaxation of the left ventricle $\left(\mathrm{dP} / \mathrm{dt}_{\text {min }}\right)$ observed here suggest that $\mathrm{rLiD} 1$ can affect the mechanisms responsible for the reduction of intracellular calcium concentration during diastole (calcium uptake by the sarcoplasmic reticulum and/or the activity of sodium calcium exchange, calcium pump present in the sarcolema).

The absence of direct effects rLiD1 on papillary muscle (peak of force developed during twitches, $\mathrm{dF}_{\mathrm{dt}} \mathrm{dtax}_{\max }$ and $\left.\mathrm{dF} / \mathrm{dt}_{\min }\right)$ suggest that the excitation contraction coupling and the contractility are not affected by the toxin. One interesting possibility is that the amount of sub products formed by the action of the toxin is insufficient to induce the effects observed in isolated hearts.

\section{Conclusion}

Recombinant toxin phospholipase D (rLiD1) did not affect directly the excitation contraction coupling or the contractility of the myocardium but its systemic effect can induces reduction in the cardiac performance.

\section{Acknowledgement}

We would like to thank CAPES for the financial support of this work.

\section{Author's Contributions}

Joao Victor Capelli Peixoto: Participated in all experiments, coordinated the data-analysis and contributed to the writing of the manuscript.

Fernando Augusto Lavezzo Dias: Participated in all experiments.

Carlos Estevan Nolf Damiani: Contributed to the data-analysis and to the writing of the manuscript.

Ilana Kassouf Silva: Contributed to the writing of the manuscript.

Silvio Sanches Veiga: Coordinated the production and quality testing of phospholipase D.

Julio Cesar Francisco: Coordinated the mouse work.
Rosalvo Tadeu Hochmueller Fogaça: Designed the research plan, organized the study and contributed to the writing of the manuscript.

\section{Ethics}

This article is original and contains unpublished material. The corresponding author confirms that all of the other authors have read and approved the manuscript and no ethical issues involved.

\section{References}

Appel, M.H., R.B. da Silveira, O.M. Chaim, K.S. Paludo and D.T. Silva et al., 2008. Identification, cloning and functional characterization of a novel dermonecrotic toxin (phospholipase D) from Brown Spider (Loxosceles Intermedia) Venom. Biochimica et Biophysica Acta-General Subjects, 1780: 167-178. DOI: 10.1016/j.bbagen.2007.11.007

Barbaro, K.C., I. Knysak, R. Martins, C. Hogan and K. Winkel, 2005. Enzymatic characterization, antigenic cross-reactivity and neutralization of dermonecrotic activity of five loxosceles spider venoms of medical importance in the Americas. Toxicon, 45: 489-499. DOI: $10.1016 /$ j.toxicon.2004.12.009

Barbaro, K.C., J.L. Cardoso, V.R. Eickstedt and I. Mota, 1992. Dermonecrotic and lethal components of loxosceles gaucho spider venom. Toxicon, 30: 331-138. DOI: 10.1016/0041-0101(92)90873-4

De Campos, D.H.S., A.S. Leopoldo, A.P. LimaLeopoldo, A.F. Do Nascimento and S.A.D. Oliveira-Junior et al., 2014. Obesity preserves myocardial function during blockade of the glycolytic pathway. Arquivos Brasileiros de Cardiologia. DOI: 10.5935/abc.20140135

Chaim, O.M., R.B. da Silveira, D. Trevisan-Silva, V.P. Ferrer and Y.B. Sade et al., 2011. Phospholipase-D activity and inflammatory response induced by brown spider dermonecrotic toxin: Endothelial cell membrane phospholipids as targets for toxicity. Biochimica et Biophysica Acta (BBA)-Molecular Cell Biol. Lipids, 1811: 84-96. DOI: 10.1016/j.bbalip.2010.11.005

Chaim, O.M., Y.B. Sade, R.B. da Silveira, L. Toma and E. Kalapothakis et al., 2006. Brown spider dermonecrotic toxin directly induces nephrotoxicity. Toxicol. Applied Pharmacol., 211: 64-77. DOI: 10.1016/j.taap.2005.05.015

Chaves-Moreira, D., F.N. Souza, R.T.H. Fogaça, O.C. Mangili and W. Gremski et al., 2011. The relationship between calcium and the metabolism of plasma membrane phospholipids in hemolysis induced by brown spider venom phospholipase-d toxin. J. Cellular Biochem., 112: 2529-2540.

DOI: $10.1002 /$ jcb. 23177 
da Silva, P.H., R.B. da Silveira, M.H. Appel, O.C. Mangili and W. Gremski et al., 2004. Brown spiders and loxoscelism. Toxicon, 44: 693-709. DOI: 10.1016/j.toxicon.2004.07.012

Dianat, M., G.R. Hamzavi, M. Badavi and A. Samarbafzadeh, 2014. Effects of losartan and vanillic acid co-administration on ischemiareperfusion-induced oxidative stress in isolated rat heart. Iranian Red Crescent Med. J., 16: e16664-e16664. DOI: 10.5812/ircmj.16664

Dias-Lopes, C., L. Felicori, G. Guimarães, E.R.M. Gomes and D. Roman-Campos et al., 2010. Cardiotoxic effects of Loxosceles intermedia spider venom and the recombinant venom toxin rLiD1. Toxicon, 56: 1426-1435. DOI: 10.1016/j.toxicon.2010.08.008

Dong, X., C.A. Sumandea, Y.C. Chen, M.L. GarciaCazarin and J. Zhang et al., 2012. Augmented phosphorylation of cardiac troponin I in hypertensive heart failure. J. Biological Chem., 287: 848-857. DOI: 10.1074/jbc.M111.293258

Futrell, J.M., 1992. Loxocelism. Am. J. Med. Sci., 304: 261-267. DOI: 10.1097/00000441-199210000-00008

Hannun, Y.A., 1996. Functions of ceramide in coordinating cellular responses to stress. Science, 274: $1855-1859$.

DOI: $10.1126 /$ science. 274.5294 .1855

Harlow, E and D. Lane, 1988. Antibodies: A Laboratory Manual. 1st Edn., CSHL Press, Cold Spring Harbor, New York, ISBN-10: 0879693142, pp: 726.

Lee, S. and K.R Lynch, 2005. Brown recluse spider (Loxosceles reclusa) venom Phospholipase D (PLD) generates Lysophosphatidic Acid (LPA). Biochem. J., 391: 317-323. DOI: 10.1042/BJ20050043
Lucato, R.V., R.C.R.M. Abdulkader, K.C. Barbaro, G.E. Mendes and I. Castro et al., 2011. Loxosceles gaucho venom-induced acute kidney injury-in vivo and in vitro studies. PLoS Negl. Trop. Dis., 5: e1182-e1182. PMID: 21655312

Peterson, M.E., 2006. Brown spider envenomation. Clin. Techn. Small Anim. Practice, 21: 191-193. PMID: 17265904

Prendes, M.G., R. Marina, M.E. Hermann, D. Torresin and E. Vélez et al., 2014. Role of mitochondrial permeability transition pore and mitochondrial atpsensitive potassium channels in the protective effects of ischemic preconditioning in isolated hearts from fed and fasted rats. J. Physiol. Biochem., 70: 791-800. PMID: 25034332

Roman, B.B., P.H. Goldspink, E. Spaite, D. Urboniene and R. McKinney et al., 2004. Inhibition of PKC phosphorylation of cTnI improves cardiac performance in vivo. Am. J. Physiol., 286: H2089-H2095. PMID: 14726296

Szkudlarek, A.C., B. Aldenucci, N.I. Miyagui, I.K. Silva and R.N. Moraes et al., 2014. Short-term thyroid hormone excess affects the heart but does not affect adrenal activity in rats. Arquivos Brasileiros de Cardiologia, 102: 270-278. PMID: 24676225

Tornquist, K., T. Blom, R. Shariatmadari and M. Pasternack, 2004. Ceramide 1-phosphate enhances calcium entry through voltage-operated calcium channels by a protein kinase C-dependent mechanism in GH4C1 rat pituitary cells. Biochem. J., 380: 661-668. PMID: 15018614 